\title{
The effect of quinidine and mexiletine on the adaptation of ventricular refractoriness to an
}

\author{
increase in rate
}

\begin{abstract}
The purpose of this study was to determine the effects of quinidine and mexiletine on the adaptation of ventricular refractoriness to a change in heart rate. The ventricular effective refractory period was measured at a basic drive cycle length of $500 \mathrm{msec}$ with basic drive train durations of two beats, eight beats, 20 beats and 3 minutes. The ventricular refractory periods were measured in the baseline state and after oral treatment with quinidine or mexiletine in 20 subjects each. In the baseline state, there was progressive shortening of the ventricular refractory period as the drive train duration increased from two beats to 3 minutes. Quinidine prolonged refractoriness by $5 \%(p<0.001)$ at each drive train duration. Mexiletine did not affect the ventricular effective refractory period at any of the drive train durations. In a control group of 20 subjects, there were no significant differences between two determinations of refractoriness at each basic drive train duration. In conclusion, neither quinidine nor mexiletine affect the adaptation of ventricular refractoriness to an increase in rate. Although the ventricular effective refractory period measured with a conventional basic drive train duration of eight beats is often more than 20 msec longer than the actual ventricular effective refractory period measured with a drive train duration of 3 minutes, the effects of quinidine and mexiletine on the conventionally measured ventricular effective refractory period accurately reflect the effects of these drugs on the actual ventricular effective refractory period. (AM HEART J 1991;121:512.)
\end{abstract}

Shimon Rosenheck, MD, Stephen Schmaltz, MPH, Alan H. Kadish, MD, Joni Summitt, DO, and Fred Morady, MD. Ann Arbor, Mich.

Ventricular refractoriness progressively shortens when there is an abrupt increase in heart rate, and several minutes at the higher heart rate may be necessary before the maximum shortening of ventricular refractoriness is attained. ${ }^{1-8}$ However, in the clinical electrophysiology laboratory, ventricular refractoriness has been conventionally measured by scanning diastole with an extrastimulus introduced after a basic drive train that is only eight beats in duration, ${ }^{9-12}$ and this method often yields a ventricular effective refractory period that is 10 to $30 \mathrm{msec}$ longer than the actual ventricular effective refractory period. ${ }^{1,13,14}$ In clinical electrophysiology studies, the effects of antiarrhythmic drugs on ventricular refractoriness have also been measured with a basic drive train duration of eight beats ${ }^{15-19}$; therefore, the effects of an-

From the Division of Cardiology and the Clinical Research Center, Department of Internal Medicine, University of Michigan Medical Center, Ann Arbor, Michigan.

Supported in part by grant 5M01-RR00042-25 from the National Institutes of Health. Bethesda, Md.

Received for publication June 14, 1990; accepted Aug. 8, 1990.

Reprint requests: Fred Morady, MD, Division of Cardiology, B1 F245 Box 0022. University of Michigan Medical Center, Ann Arbor. MI 48109. 4/1/25695 tiarrhythmic drugs on the actual ventricular effective refractory period are not known. Depending on the effect of an antiarrhythmic drug on the adaptation of ventricular refractoriness to an increase in rate, the conventionally measured ventricular effective refractory period may or may not accurately reflect the effect of the drug on the actual ventricular effective refractory period.

The purpose of this study was to determine the effects of quinidine and mexiletine on the adaptation of ventricular refractoriness to an increase in heart rate. Quinidine and mexiletine were selected for this study because they are commonly used representatives of class IA and IB antiarrhythmic drugs. ${ }^{20}$ Our aim was to determine whether the effects of these drugs on the conventionally measured effective refractory period accurately reflect their effects on the actual ventricular effective refractory period.

\section{METHODS}

Subjects of study. The subjects of this study were 54 patients who underwent clinically indicated electrophysiology tests for evaluation of ventricular tachycardia, unexplained syncope, or paroxysmal supraventricular tachycardia. There were 48 men and 6 women, and their mean age 
was $61 \pm 12$ years ( \pm standard deviation). Forly palients had coronary artery disease, six patients had cardiomyopathy, and eight patients had no structural heart disease. The mean left ventricular ejection fraction determined by echocardiography or contrast or radionucleide ventriculography was $0.43 \pm 0.14$. 'Thirty-four of these subjects had sustained monomorphic ventricular tachycardia that was inducible by programmed stimulation, and they underwent drug testing; the effects of quinidine and mexiletine were assessed in 20 electrophysiology tests each. An additional 20 subjects served as a control group. Patients were not selected as subjects for this study if they were not in sinus rhythm at a cycle length longer than $600 \mathrm{msec}$, if ventricular tachycardia or paroxysmal supraventricular tachycardia was inducible with a single ventricular extrastimulus, or if 3 minutes of ventricular pacing at a cycle length of 500 msec was not hemodynamically tolerated.

Electrophysiology protocol. Electrophysiologic studies were performed in the fasting, unsedated state and after informed consent was obtained, either at least five halflives after discontinuation of treatment with antiarrhythmic drugs or after at least 2 days of treatment with quinidine or mexiletine. Two to four quadripolar electrode catheters $(1 \mathrm{~cm}$ electrode spacing) were inserted into a femoral or subclavian vein and positioned as clinically indicated in the right atrium, His bundle position, coronary sinus, or right ventricle. Electrocardiographic leads $\mathrm{V}_{1}, \mathrm{I}$, and III, and the intracardiac electrograms were recorded on a Siemens Elema Mingograph 7 recorder (Siemens Medical Systems Inc., Iselin, N.J.) at a paper speed of 25 to 100 $\mathrm{mm} / \mathrm{sec}$. Bipolar pacing was performed with the distal pair of electrodes with the use of a programmable stimulator (Bloom Associates Ltd., Reading, Pa.). The pacing stimuli were $2 \mathrm{msec}$ in duration and had a current strength twice that of the late diastolic threshold.

Study protocol. The study protocol was approved by the Human Research Committee and was performed on completion of the clinically indicated portion of the electrophysiology test. An electrode catheter was positioned in the right ventricular apex, and a stable position in which the pacing threshold was less than $0.8 \mathrm{~mA}$ was obtained with fluoroscopic guidance. The ventricular effective refractory period was measured with a pacing drive cycle length of 500 msec and drive train durations of two beats, eight beats, 20 beats, and 3 minutes. The 3 -minute drive train was used because an earlier study demonstrated that this is sufficient to yield the maximum shortening of ventricular refractoriness when the drive train cycle length is 400 to 600 msec. ${ }^{1}$ The initial beat of the drive train was synchronized always to occur $500 \mathrm{msec}$ after a sinus beat. If there was ventriculoatrial dissociation, the atrium was paced simultaneously with the ventricle to avoid disruption of the basic drive train by sinus capture beats. The drive trains of two, eight, and 20 beats were separated by an intertrain pause of 3 seconds. When the drive train duration was 3 minutes, the drive train was not interrupted by pauses and the extrastimulus was inserted after every eighth beat of the drive train.

A ventricular extrastimulus was introduced at an initial coupling interval that was shorter than the ventricular effective refractory period. The coupling interval was progressively increased in steps of $2 \mathrm{msec}$ until ventricular capture was elicited, and the ventricular effective refractory period was defined as the longest coupling interval that did not evoke a ventricular response. The ventricular effective refractory period was measured in this fashion because an earlier study demonstrated that this method yields a more accurate ventricular effective refractory period than when the extrastimulus coupling interval is initially longer than the ventricular refractory period and the coupling interval is progressively shortened until ventricular capture is lost. ${ }^{21}$

Ventricular effective refractory periods were measured in the control state and after at least 2 days of oral treatment with a mean of $1.4 \pm 0.6 \mathrm{gm} /$ day of quinidine (mean plasma concentration, $2.4 \pm 0.7 \mu \mathrm{g} / \mathrm{ml}$ ) in 20 subjects, and in the control state and after at least 2 days of oral treatment with a mean of $675 \pm 100 \mathrm{mg} /$ day of mexiletine (mean plasma concentration $1.3 \pm 0.7 \mu \mathrm{g} / \mathrm{ml}$ ) in $20 \mathrm{sub}$ jects. In six of these subjects, a single control study was followed by serial testing with mexiletine and quinidine, whereas in 28 subjects a control study was followed by a single drug study with either quinidine or mexiletine.

Control group. The reproducibility of the techniques that were used in this study to determine the adaptation of ventricular refractoriness to an increase in heart rate was assessed in a control group of 20 subjects. In these subjects, ventricular effective refractory periods were measured at the beginning of an electrophysiology test and again 45 to 90 minutes later, on completion of the clinically indicated portion of the electrophysiology test. The electrode catheter that was used to measure the ventricular effective refractory periods was purposely moved out of the right. ventricular apex and repositioned in the same general area before the second set of measurements to simulate the catheter repositioning that occurred in the subjects who underwent the control study and a drug study on different days.

Statistics. To determine the effects of the basic drive train duration and the two drugs on ventricular refractoriness, a repeated measures analysis of variance was used. ${ }^{22}$ Multiple comparisons were performed using Fisher's least significant difference multiple comparisons procedure. ${ }^{23}$ The reproducibility of the baseline measurements of refractoriness was ascertained by calculating a reliability estimate at each basic drive train duration. ${ }^{24} \mathrm{~A} p$ value of less than 0.05 was considered significant.

\section{RESULTS}

Effects of quinidine. In the baseline state in 20 subjects, the ventricular effective refractory period progressively shortened as the basic drive train duration increased (Fig. 1). Quinidine significantly lengthened the ventricular effective refractory period at each basic drive train duration (Fig. 1). There were no significant differences in the magnitude of quinidine's effects on the ventricular refractory period, either in 


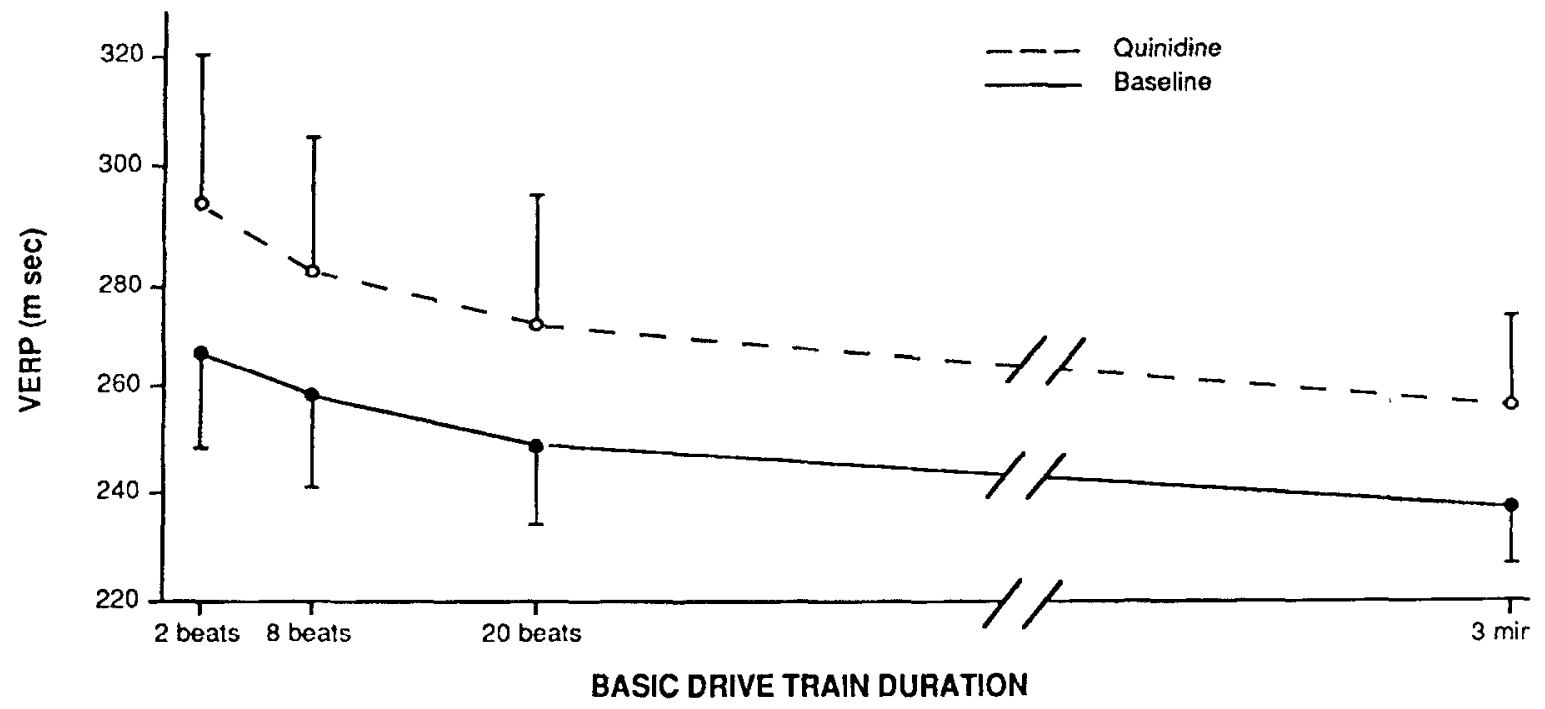

Fig. 1. The effect of quinidine on the adaptation of the ventricular effective refractory period $(V E R P)$ to an increase in rate. Quinidine significantly lenghened refractoriness at each drive train duration $(p<0.001)$.

Table I. Absolute and percent change in ventricular effective refractory period caused by quinidine in 20 subjects

\begin{tabular}{ccccc}
\hline & \multicolumn{4}{c}{ Basic drive train duration } \\
\cline { 2 - 5 } & $\begin{array}{c}\text { Two } \\
\text { beats }\end{array}$ & $\begin{array}{c}\text { Eight } \\
\text { beats }\end{array}$ & 20 Beats & 3 Minutes \\
\hline $\begin{array}{c}\text { Absolute change } \\
\text { from baseline }\end{array}$ & $29 \pm 21^{*}$ & $24 \pm 15^{*}$ & $22 \pm 17^{*}$ & $21 \pm 14^{*}$ \\
$\begin{array}{c}\text { Percent change } \\
\text { from baseline }\end{array}$ & $11 \pm 4$ & $9 \pm 3$ & $9 \pm 4$ & $8 \pm 2$ \\
\hline
\end{tabular}

Values are expressed as mean \pm standard deviation.

There were no significant diflerences in the absolute or percent changes from the haseline among the various basic drive train durations.

${ }^{*} p<0.001$ when compared to baseline.

absolute terms or when expressed as percent change, among the different basic drive train durations ( $\mathrm{Ta}$ ble I). Quinidine did not significantly change the mean resting sinus cycle length $(841 \pm 189 \mathrm{msec}$ baseline vs $822 \pm 147 \mathrm{msec}$ with quinidine).

Effects of mexiletine. In the baseline state in 20 subjects, the ventricular effective refractory period progressively shortened as the basic drive train duration increased, in a fashion identical to the ventricular effective refractory periods in the baseline studies of the subjects who were treated with quinidine (Fig. 2). Mexiletine did not significantly affect the ventricular effective refractory period at any of the basic drive train durations (Fig. 2). Mexiletine also did not significantly affect the mean resting sinus cycle length $(810 \pm 157 \mathrm{msec}$ baseline vs $824 \pm 149$ msec with mexiletine).

Control group. There were no significant differences between the two determinations of ventricular refractoriness at each drive train duration in the 20 subjects in the control group (Table II). The reliability estimate for the measurements of refractoriness ranged from 0.9 for the 3 -minute drive train duration to 0.97 for the 20 -beat drive train duration.

\section{DISCUSSION}

Main findings. In this study, ventricular effective refractory periods were measured in the baseline state with basic drive train durations of two beats, eight beats, 20 beats, and 3 minutes to define the time course of adaptation of ventricular refractoriness to an increase in heart rate. As expected, the ventricular effective refractory period was found to shorten progressively as the duration of the basic drive train increased to 3 minutes. The results of this study demonstrate that neither quinidine nor mexiletine affect the adaptation of ventricular refractoriness to an increase in heart rate. At a drive cycle length of 500 msec, quinidine significantly lengthened the ventricular effective refractory period, and there was no interaction between quinidine's effects and the duration of the basic drive train. Mexiletine had no significant effect on the ventricular effective refractory period, regardless of the duration of the basic drive train. Therefore although quinidine and mexiletine differ in that the former prolongs ventricular refractoriness whereas the latter does not, both drugs are similar in that neither one alters the time course of progressive shortening in the ventricular effective refractory period that occurs as the duration of the basic drive train increases to 3 minutes. 


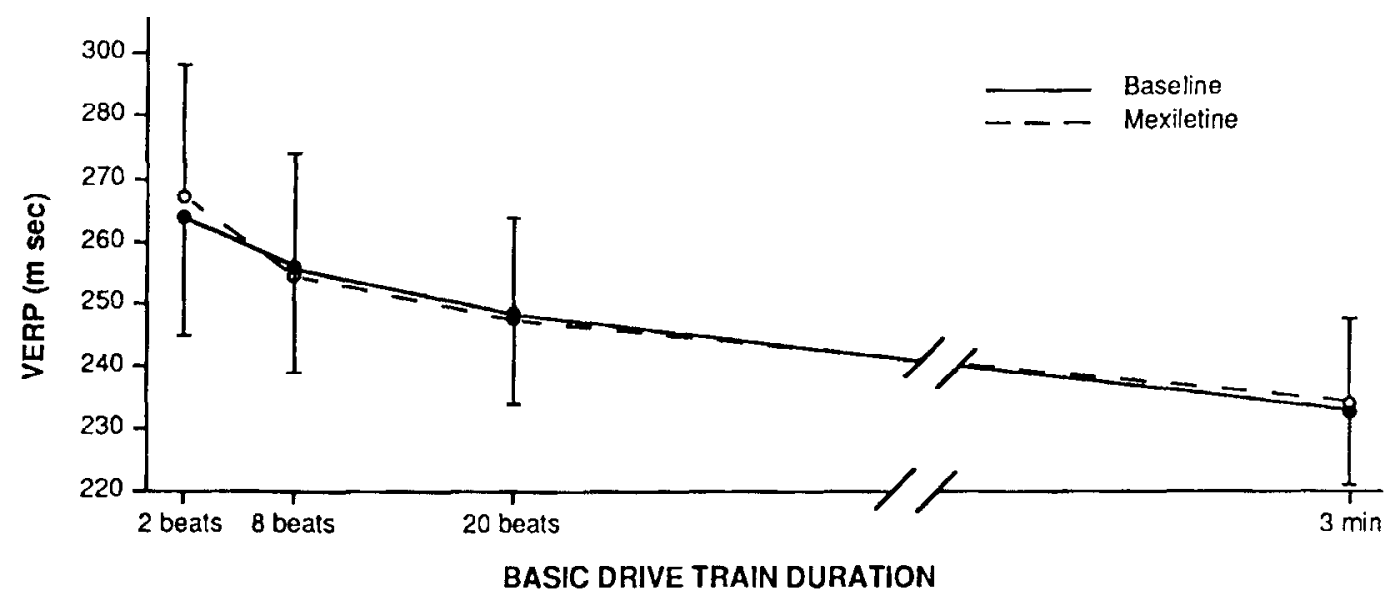

Fig. 2. The effect of mexiletine on the adaptation of the ventricular effective refractory period (VERP) to an increase in rate. Mexiletine had no effect on refractoriness at any of the drive train durations.

Reproducibility of measurements. The results that were obtained from the 20 subjects in the control group demonstrated a mean difference of $1 \pm 6 \mathrm{msec}$ between two determinations of the ventricular effective refractory period at a given basic drive train duration, and this difference was not significant. These findings provide validation that the lengthening of refractoriness that occurred during treatment with quinidine was in fact attributable to a drug effect and that a systematic drug effect was not present in the subjects who were treated with mexiletine.

Use-dependent effects of quinidine and mexiletine. Experimental studies have demonstrated that the effects of antiarrhythmic drugs that block sodium channels such as quinidine and mexiletine, are usedependent. ${ }^{25-29}$ In concert with the findings of experimental studies, clinical studies have demonstrated that the effects of class I antiarrhythmic drugs and amiodarone on His-Purkinje and intraventricular conduction are also use-dependent. ${ }^{19}, 30-32$ In regard to the ventricular effective refractory period, experimental studies have demonstrated that class I drugs, including quinidine and mexiletine, have frequencydependent effects on the ventricular effective refractory period, ${ }^{27,33,34}$ and an earlier clinical study demonstrated that procainamide has use-dependent effects on ventricular refractoriness. ${ }^{35}$ However, no previous clinical studies have investigated the usedependent effects of quinidine or mexiletine on the ventricular effective refractory period. Depending on the binding and dissociation kinetics of these drugs, effects on the ventricular effective refractory period might be expected to be less pronounced after a drive train of two beats than after drive trains of eight beats or more. However, because pacing was performed only at a single cycle length of $500 \mathrm{msec}$, no
Table II. Two determinations of the ventricular effective refractory period in 20 control subjects

\begin{tabular}{lcccc}
\hline & \multicolumn{4}{c}{ Basic drive train duration } \\
\cline { 2 - 5 } & $\begin{array}{c}\text { Two } \\
\text { beats }\end{array}$ & $\begin{array}{c}\text { Eight } \\
\text { beats }\end{array}$ & 20 Beats & 3 Minutes \\
\hline First determination & $264 \pm 26$ & $253 \pm 24^{*}$ & $244 \pm 22^{*}$ & $227 \pm 13^{*}$ \\
Second determination & $264 \pm 26$ & $253 \pm 24^{*}$ & $245 \pm 23^{*}$ & $229 \pm 15^{*}$
\end{tabular}

Values are expressed as mean \pm standard deviation.

There were no significant differences between the two determinations of re. fractoriness at any of the drive train durations.

${ }^{*} p<0.001$ when compared to preceding drive train duration

conclusions can be drawn in regard to the presence or absence of use-dependent effects of quinidine or mexiletine on ventricular refractoriness.

Limitations. A limitation of this study is that the adaptation of ventricular refractoriness to an increase in heart rate was determined with only a single pacing cycle length of $500 \mathrm{msec}$. The results that were obtained at this cycle length may not be applicable to other cycle lengths. A second limitation is that serial measurements of the ventricular effective refractory period in the control group were obtained in the course of a single electrophysiology test, and day-to-day variability in the measurement of the ventricular effective refractory period therefore was not controlled. The third limitation is that the use of a 3-second intertrain pause when the ventricular effective refractory period was measured may have allowed for a cumulative effect of the basic drive trains on the ventricular effective refractory periods; therefore, the ventricular effective refractory periods that were measured during basic drive trains of two, eight, and 20 beats may have been influenced not only by 
the number of beats in the drive train but also by the total number of drive trains that preceded the particular drive train that defined the ventricular effective refractory period. Finally, we cannot rule out the possibility that higher plasma drug concentrations than those tested in this study would have yielded different results.

Conclusions. Because ventricular refractoriness adapts to an increase in heart rate in a gradual fashion, the conventional method of determining the ventricular effective refractory period with a basic drive train of eight beats does not yield an accurate measurement of the actual ventricular effective refractory period. When the basic drive train cycle length is $500 \mathrm{msec}$, the conventionally measured ventricular effective refractory period overestimates the actual ventricular effective refractory period by a mean of more than 20 msec. Nevertheless, because neither quinidine nor mexiletine affects the adaptation of ventricular refractoriness to an increase in heart rate, the effects of these drugs on the conventionally measured ventricular effective refractory period are similar in magnitude to their effects on the actual ventricular effective refractory period. Therefore although conventional measurements of ventricular refractoriness are inaccurate in absolute terms, the change in ventricular effective refractory period that results from treatment with quinidine or mexiletine can be accurately determined regardless of the duration of the basic drive train, at least when the cycle length of the basic drive train is $500 \mathrm{msec}$.

The authors are grateful to Deanne Backhaus and Marion Maguire for assistance in preparation of the manuscript.

\section{REFERENCES}

1. Morady F, Kadish AH, Toivonen LK, Kushner JA, Schmaltz $\mathrm{S}$. The maximum effect of an increase in rate on human ventricular refractoriness. PACE 1988;11:2223-34.

2. Gibbs CL, Johnson EA. Effect of change in frequency of stimulation upon rabbit ventricular action potential. Circ Res 1961;9:165-70.

3. Janse MJ, van der Steen ABM, van Dam RTh, Durrer D. Refractory period of the dog's ventricular myocardium following sudden change in frequency. Circ Res 1969;24:251-62.

4. Vick RL. Action potential duration in canine Purkinje tissue: effects of preceding excitation. J Electrocardiol 1971;4:105-15.

5. Miller JP, Wallace AG, Feezor MD. A quantitative comparison of the relation between the shape of action potential and the pattern of stimulation in canine ventricular muscle and Purkinje fibers. J Moll Cell Cardiol 1971;2:3-19.

6. Boyett MR. An analysis of the effect of the rate of stimulation and adrenaline on the duration of the cardiac action potential. Pfluger Archiv 1978;377:155-66.

7. Lab MJ, Yardley J. Electrophysiological differences between apex and base in intact pig ventricle. J Physiol 1979;292:62P. $63 \mathrm{P}$.

8. Boyett MR, Jewell BR. Analysis of the effect of change in rate and rhythm upon electrical activity in the heart. Prog Biophys Mol Biol 1980;36:1-52.

9. Cooper MJ, Koo CC, Skinner MP, Mortensen PT, Hunt LJ, Richards DA, Uther JB, Ross DL. Comparison of immediate versus day by day variability of ventricular tachycardia induction by programmed stimulation. $\mathrm{J}$ Am Coll Cardiol 1989;13:1599-607.

10. Vassalo JA, Marchlinski FE, Cassidy DM, Buxton AE, Josephson ME. Shortening of ventricular refractoriness with extrastimuli: role of the degree of prematurity and number of extrastimuli. J Electrophysiol 1988;2:227-36.

11. Estes III NAM, Garan H, McGovern B, Ruskin JN. Influence of drive cycle length during programmed stimulation on the induction of ventricular arrhythmias: analysis of 403 patients. Am J Cardiol 1986;57:108-12.

12. Morady F, Kou WH, Kadish AH, Kadish AH, Schmaltz S, Summitt J, Rosenheck S. Effect of basic train cycle length on induction of ventricular tachycardia by a single extrastimulus. $J$ Electrophysiol 1989;3:111-16.

13. Prystowsky EN, Miles WN. Human ventricular refractoriness: Interdependency of drive train duration, current strength and heart rate [abstract]. J Am Coll Cardiol 1984;3:537.

14. Brownstein SL, Buaernfeind R, Welsh W, Blackwell W, Constantin L. Cumulative effect of cycle length on ventricular refractoriness in man [abstract]. PACE 1987;10:432.

15. DiMarco JP, Garan H, Ruskin JN. Quinidine for ventricular arrhythmias: value of electrophysiologic testing. Am J Cardiol 1983;51:90-5.

16. Morady F, Kou WH, Kadish AH, Nelson SD, Toivonen LK, Kushner JA, Schmaltz S, deBuitler M. Antagonism of quinidine's electrophysiologic effects by epinephrine in patients with ventricular tachycardia. J Am Coll Cardiol 1988;12:38894

17. Morady F, DiCarlo LA, deBuitleir M, Krol RB, Baerman JM. Effect of incremental dose of procainamide on ventricular re fractoriness, intraventricular conduction, and induction of ventricular tachycardia. Circulation 1986;74:1355-64.

18. Rinkenberger RL, Pristowski EN, Jackman WM, Nacarelli GV, Heger JJ, Zipes DP. Drug conversion of nonsustained ventricular tachycardia during serial electrophysiologic studies: identification of drugs that exacerbate tachycardia and potential mechanisms. AM HEART J 1982;103:177-84.

19. Marchlinski FE, Buxton AE, Kindwall E, Miller JM, Rosenthal ME, Gottlieb CD, Blood RB, Josephson ME. Comparison of individual and combined effect of procainamide and amiodarone in patients with sustained ventricular tachycardia. Circulation 1988;78:583-91.

20. Vaugham Williams EM. A classification of antiarrhythmic action reassessed after a decade of new drugs. J Clin Pharmacol $1984 ; 24: 129-47$.

21. Morady F, Kadish AH, Kushner JA, Toivonen LK, Schmaltz S. Comparison of ventricular refractory periods determined by incremental and decremental scanning of an extrastimulus. PACE 1989;12:546-54.

22. Berk K. Computing for incomplete repeated measured. Biometrics 1987;43:385-98.

23. Milliken GA, Johnson DE. Analysis of messy data. Volume I: designed experiments. New York: Van Nostrand Reinhold, 1984:322-50.

24. Winer DG. Statistical principles in experimental design. New York: McGraw Hill Book Co., 1971:283-96.

25. Hondeghem L, Katzung BG. Test of a model of anti arrhythmic drug action: effect of quinidine and lidocaine on myocardial conduction. Circulation 1980;61:1217-24.

26. Shen X, Antzelevitch C. Mechanisms underlying the antiarrhythmic and arrhythmogenic action of quinidine in a Pukinje Fiber-ischemic gap preparation of reflected reentry. Circulation 1986;73:1342-53.

27. Roden DM, Iansmith DHS, Wonsley RL. Frequency-depen- 
dent interactions of mexiletine and quinidine on depolarization and repolarization in canine Purkinje Fibers. J Pharmacol Exp Ther 1987;243:1218-24.

28. Clarkson CW, Hondeghem LC. Evidence for a specific receptor site for lidocaine, quinidine, and bipivacaine associated with cardiac sodium channels in guinea pig ventricular myocardium. Circ Res 1985;56:496-506.

29. Bajaj AK, Kopelman HA, Wikswo JP, Cassidy F, Kopelman HA, Woosey RL, Roden DM. Frequency-and orientation-dependent effect of mexiletine and quinidine on the conduction in the intact dog heart. Circulation 1987;75:1065-73.

30. Mercer AB, Foster JR, Simpson RJ Jr, Bettes LS. Use-dependency of antiarrhythmic drugs in the human heart [abstract]. Circulation 1983;68 (suppl III):III-286.

31. Morady F, DiCarlo L Jr, Baerman J, Krol RB. Rate-dependent effect of lidocaine, procainamide and amiodarone on intraventricular conduction. J Am Coll Cardiol 1985;6:179-85.
32. Gang ES, Denton TA, Oseran DS, Mandel WJ, Peter T. Ratedependent effect of procainamide on His-Purkinje conduction in man. 1985;55:1525-9.

33. Nattel S, Zeng FD. Frequency-dependent effects of antiarrhythmic drugs on action potential duration and refractoriness of canine cardiac Purkinje fibers. J Pharmacol Exp Ther 1984;229:283-91.

34. Franz MR, Costard A. Frequency-dependent effect of quinidine on the relationship between action potential duration and refractoriness in the canine heart in situ. Circulation 1988; 77:1177-84.

35. Marchlinski FE, Shinnar M. Cycle length dependent effect of procainamide on ventricular refractoriness [abstract]. J Am Coll Cardiol 1987;9:227A.

\title{
Effect of hyperkalemia on experimental myocardial depression by verapamil
}

\begin{abstract}
Three patients with systemic hypotension and sinus bradycardia that were initially refractory to conventional therapy responded well to intravenous calcium administration. Two-dimensional echocardiography revealed immediate reversal of severe left ventricular dysfunction after intravenous administration of calcium in two instances. Common factors were hyperkalemia and verapamil therapy. This interaction was examined further by evaluation of contractility, heart rate, and arterial blood pressure in anesthetized dogs. Controls $(n=9)$ received saline infusion, and a second group $(n=10)$ received saturated potassium chloride (approximately $0.2 \mathrm{ml} / \mathrm{min}$ intravenously). In control dogs, administration of verapamil (1195 $\pm 181 \mu \mathrm{g} / \mathrm{kg}$ intravenously) reduced systemic arterial pressure from $113 \pm 7 \mathrm{~mm} \mathrm{Hg}$ to $74 \pm 5 \mathrm{~mm} \mathrm{Hg}$, and heart rate from $147 \pm 9$ beats $/ \mathrm{min}$ to $86 \pm 11$ beats $/ \mathrm{min}$. Potassium chloride infusion alone increased blood $\left[\mathrm{K}^{+}\right]$from $3.4 \pm 0.1$ to $6.2 \pm 0.2 \mathrm{mEq} / \mathrm{L}$, but was without hemodynamic effects. In hyperkalemic dogs, a significantly lower dose of verapamil (428 $\pm 42 \mu \mathrm{g} / \mathrm{kg}$ intravenously) reduced systemic arterial pressure from $102 \pm 8 \mathrm{~mm} \mathrm{Hg}$ to $36 \pm 4 \mathrm{~mm} \mathrm{Hg}$, and heart rate from $150 \pm 5 \mathrm{beats} / \mathrm{min}$ to $104 \pm 15$ beats $/ \mathrm{min}$. Myocardial contractile function was examined with right ventricular isometric contractile force and left ventricular segment length changes. In normokalemic and hyperkalemic groups, contractility was decreased by verapamil. Effects of verapamil on arterial pressure and contractility could be reversed significantly by administration of calcium, 0.4 $\mathrm{mEq} / \mathrm{kg}$ intravenously. The present results support the theory that the negative hemodynamic effects of verapamil may be exaggerated to a harmful degree by concomitant hyperkalemia. These adverse events may be reversed by calcium administration. (AM HEART J 1991;121:517.)
\end{abstract}

Stanley R. Jolly, PhD, Nancy Keaton, MD, Assad Movahed, MD, Gregory C. Rose, MD, and William C. Reeves, MD. Greenville, N.C.

Verapamil $1^{1-3}$ is one of the first calcium channel blockers to be used clinically for the treatment of

From the Cardiology Section, Department of Internal Medicine, East Carolina University School of Medicine, Greentille, N.C.

Received for publication Apr. 18, 1990; accepter Aug. 6, 1990

Reprint requests: Assad Movahed, MD, Cardiology Section, Department of Medicine, East Carolina University School of Medicine, Greenville, NC 27858-4354.

$4 / 1 / 25681$ systemic hypertension, supraventricular tachyarrhythmias, and angina pectoris. High doses of verapamil can produce significant myocardial depression with reduced ventricular contractility, sinus bradycardia, atrioventricular conduction delay, and systemic hypotension. ${ }^{4,5}$ Clinical and experimental studies have suggested when adverse exaggerated responses to verapamil could be expected to occur. For example, intravenous verapamil plus $\beta$-adrenergic 